\title{
ANALISIS PEMASARAN JERUK SIAM (Studi Kasus: Desa Lasembangi Kecamatan Lasalimu Kabupaten Buton)
}

\author{
Muzuna \\ Program Studi Agribisnis Fakultas Pertanian \\ Universitas Muhammadiyah Buton \\ Jl.Betoambari No. 36 Baubau \\ e-mail: muzunaumb@gmail.com
}

\begin{abstract}
This research has been conducted in Lasembangi Village, Lasalimu Subdistrict of Buton around June and July 2012. The aim of this study is to identify the types of marketing channels in Lasembangi Village, Lasalimu Subdistrict of Buton, to determine the marketing functions performed on each marketing channel, to determine the share profit producers in each marketing channel to determine the marketing efficiency of each marketing channel in Lasembangi Village, Lasalimu Subdistrict of Buton. The sampling method used by a tangerine farmer in the village of Lasembangi by Simple Random Sampling with 30 farmers randomly selected a sample of 120 farmers as a population. Sample totaling 3 traders and retailers 6 . The data collected in this study consisted of primary data and secondary data. The data obtained from the field beforehand in a simple tabulated and analyzed in accordance with appropriate methods of analysis. Total samplings were 3 traders and 6 retailers. The data collected in this analysis consisted of primary and secondary data. Data obtained from the field in advance in a simple tabulated and evaluated in accordance with the correct methods of analysis. When the Ep price is $\leq 50$ percent, Studies and analysis show that in this field of research there are three or more types of marketing channels: Channel 1: Farmer / Two Customer, Channel 2: Farmer / Towards Traders / Channel 3: Channel 1: Farmer / Towards the Market. On each marketing channel, marketing roles are performed the same. The share profit margin of manufacturers is different for every marketing channel. Networks I share 33.90\%, Channels II 17.48\% and Channels III 19.76\%. In the village of Lasembangi, citrus marketing networks are already functioning.
\end{abstract}

Keywords: Orange, channel marketing, marketing margins, share profit margins, marketing efficiency

\begin{abstract}
Abstrak
Penelitian dilaksanakan di Desa Lasembangi Kecamatan Lasaiimu Kabupaten Buton pada Bulan Juni sampai dengan Juli 2012. Penelitian ini bertujuan untuk mengetahui jenis-jenis saluran pemasaran di Desa Lasembangi Kecamatan Lasaiimu, untuk mengetahui fungsifungsi pemasaran yang dilakukan pada setiap saluran pemasaran, untuk mengetahui share margin profit produsen pada setiap saluran pemasaran untuk mengetahui efisiensi pemasaran untuk setiap saluran pemasaran di Desa Lasembangi Kecamatan Lasalimu. Metode penentuan sampel petani'jeruk siam di Desa Lasembangi dilakukan dengan metode Simple Random Sampling dengan memilih 30 petani secara acak sebagai sampel dari 120 petani sebagai populasi. Sampel pedagang pengumpul beijumlah 3 orang dan pedagang pengecer 6 . Data yang dikumpulkan dalam penelitian ini terdiri dari data primer dan data sekunder. Data
\end{abstract}




\section{Media Agribisnis}

\section{Vol. 3, Issue 2, November 2019}

\section{P-ISSN: 2527-8479 E-ISSN: 2686-2174}

yang diperoleh dari lapangan terlebih dahulu ditabulasi secara sederhana dan selanjutnya dianalisis sesuai dengan metode analisis yang sesuai. Bila nilai Ep $<50 \%$. Hasil penelitian dan pembahasan menunjukan bahwa terdapat 3 macam atau 3 jenis saluran pemasaran di daerah penelitian ini yaitu saluran I: Petani produsen $\rightarrow$ Konsumen, saluran II: Produsen $\rightarrow$ Pedagang Pengecer $\rightarrow$ Konsumen, dan saluran III: Produsen $\rightarrow$ Pedagang Pengumpul $\rightarrow$ Konsumen. Fungsi-fungsi pemasaran yang dilakukan pada setiap saluran pemasaran adalah sama. Share margin profit produsen adalah berbeda-beda untuk setiap saluran pemasaran. Share margin saluran I 33,90\%, saluran II 19,76\% dan saluran III 17,48\%. Saluran pemasaran jeruk siam di Desa Lasembangi sudah efisien.

Kata kunci: Jeruk siam, saluran pemasaran, margin pemasaran, share margin profit, efisiensi pemasaran

\section{PENDAHULUAN}

Pada enam tahun terakhir (2005-2011), luas panen dan produksi buah jeruk di Indonesia mengalami peningkatan yang cukup pesat yaitu masing-masing $17,9 \%$ dan $22,4 \%$. Pada tahun 2004, luas panen jeruk telah mencapai 70.000 ha dengan total produksi sebesar 1.600 .000 ton. Kondisi ini menempatkan Indonesia sebagai negara penghasil utama jeruk setelah Vietnam. Produktivitas jeruk Indonesia jauh lebih tinggi dibandingkan dari produksi negara tetangga, tetapi sebagian besar produksi itu diserap oleh pasar domestik (Ashari, 2004). Pola usahatani yang masih bersifat tradisional rnenyebabkan lemahnya pemasaran buah-buahan di Indonesia. Untuk itu, perlu penanganan yang khusus sejak persiapan hingga dipasarkan (Rahardi, dkk. 2004). Kepala Balai Proteksi Tanaman Pangan dan Hortikultura Dinas Pertanian Sulawesi Tenggara mengatakan bahwa persoalan jeruk terletak pada pemasarannya. Pemerintah daerah dapat menolong petani dengan membuka jalur pemasaran (Hidayat, 2006). Masalah yang ditemui petani dalam pemasaran adalah bagaimana agar hasil-hasil pertanian dapat memberikan keuntungan yang layak dan wajar ketika panen. Petani jeruk pada umumnya menghadapi masalah fluktuasi harga.Pada saat panen besar, jeruk siam di tingkat petani dijual dengan harga Rp. 2.500 sampai Rp. 3.000 per kg. Umumnya harga jual jeruk di kebun sekitar Rp. $2.500 / \mathrm{kg}$, sedangkan biaya yang dikeluarkan untuk memproduksi buah jeruk mencapai Rp.1500 per kg. Harga jual jeruk pada panen raya mengalami penurunan tajam. Penurunan ini disebabkan belum berhasilnya Pemerintah Kabupaten Buton menerobos pasar regional dan nasional, serta belum adanya produk olahan dari buah jeruk (Ginting, 2006).

Fluktuasi harga buah jeruk sangat dipengaruhi oleh dinamika ketersediaan produk yang terjadi di pasar. Mutu buah jeruk yang dihasilkan petani relatif rendah dengan penampilan yang kurang menarik. Penampilan jeruk yang dijual umumnya buruk, kusam dan rasanya beragam. Hal ini mengakibatkan lemahnya daya saing untuk penentrasi pasar domestik segmen xertentu apalagi pasar luar negeri. Di pasar domestik, jeruk siam dari Kecamatan Lasembangi masih bersaing dengan jeruk impor yang kualitasnya jauh lebih baik. Tingginya kualitas ini ditentukan oleh rasa, penampilan dan harga. Pemasaran buah jeruk di dalam negeri mempunyai prospek yang cukup cerah. Selera dan permintaan pasar akan buah jeruk tampak cukup besar dan makin meningkat, apabila mutunya ditingkatkan (Joesoef, 1993).

Kecamatan Lasalimu memberikan kontribusi jeruk yang sangat besar terhadap Kabupaten Buton pada tahun 2011 yaitu sebesar 29.789 kwintal atau 78,37\% dibanding 
dengan kecamatan lainnya. Dengan demikian Kecamatan Lasalimu menempati peringkat pertama dalam produksi buah jeruk siam untuk Kabupaten Buton.

Walaupun Kecamatan Lasalimu sudah bisa menghasilkan jeruk dengan jumlah produksi yang tinggi yaitu sebesar 29.789 kwintal, namun petani masih mengalami masalah dalam pemasaran buah jeruk. Di Desa Lasembangi Kecamatan Lasalimu belum diketahui bagaimana jenis saluran pemasaran, fungsi-fungsi pemasaran, biaya pemasaran, marketing margin, price spread dan share margin serta efisiensi pemasaran. Oleh karena itu penulis tertarik melakukan penelitian ini.

Adapun tujuan penelitian yang dilakukan adalah :

1. Untuk mengetahui jenis-jenis saluran pemasaran di Desa Lasembangi Kecamatan Lasalimu.

2. Untuk mengetahui fungsi-fungsi pemasaran yang dilakukan pada setiap saluran pemasaran.

3. Untuk mengetahui share margin profit produsen pada setiap saluran pemasaran.

4. Untuk mengetahui efisiensi pemasaran untuk setiap saluran pemasaran di Desa Lasembangi Kecamatan Lasalimu.

\section{METODE PENELITIAN}

Penelitian ini dilaksanakan pada Bulan Juni sampai dengan Juli 2012 di Desa Lasembangi Kecamatan Lasalimu Kabupaten Buton.

\section{a. Petani}

Metode penentuan sampel petani jeruk siam di Desa Lasembangi dilakukan dengan metode Simple Random Sampling dengan memilih 30 petani secara acak sebagai sampel dari 120 petani sebagai populasi. Besar sampel tersebut dianggap mewakili populasi. Penentuan besar sampel yang hanya 30 petani bertujuan untuk mempennudah dan mempercepat proses penelitian (Singarimbuni, 1989).

\section{b. Pedagang atau Lembaga Pemasaran}

Sampel pedagang adalah orang-orang yang terlibat dalam mendistribusikan jeruk siam hasil produksi petani hingga ke konsumen akhir. Pedagang perantara ditentukan dengan metode penelusuran yaitu dengan menelusuri semua pedagang yang terlibat dan yang mengambil jeruk siam hasil produksi petani sampel di Desa Lasembangi Kecamatan Lasalimu mulai dari pedagang pengumpul dan pedagang pengecer.

Data yang dikumpulkan dalam penelitian ini terdiri dari data primer dan data sekunder. Data primer diperoleh melalui wawancara langsung dengan petani dan pedagang dengan menggunakan kuisioner yang telah disusun sebelumnya. Data sekunder diperoleh dari Dinas Pertanian Kabupaten Buton dan Badan Pelaksana Penyuluhan Pertanian, Perikanan, Kehutanan dan Ketahanan Pangan Kabupaten Buton.

Variabel penelitian ini meliputi :

1. Karakteristik responden, yaitu umur petani, pendidikan, pengalaman berusahatani dan jumiah tanggungan keluarga.

2. Karakteristik pedagang, yaitu umur petani, pendidikan, pengalaman berdagang dan 
jumiah tanggungan keluarga.

3. Deskripsi usahatani, yaitu luas lahan garapan, produksi.

4. Harga penjualan oleh petani, harga pembelian dan harga penjualan pada tiap lembaga pemasaran yang ada, biaya pemasaran yang dikeluarkan oleh lembaga pemasaran.

\section{Teknik Analisis Data}

Data yang diperoleh dari lapangan terlebih dahulu ditabulasi secara sederhana dan selanjutnya dianalisis sesuai dengan metode analisis yang sesuai.Untuk menguji hipotesis (1) diuji dengan analisis deskriptif berdasarkan survey dan pengamatan yang dilakukan di daerah penelitian.

Hipotesis yang digunakan adalah :

- Ho : Jenis saluran pemasaran hanya satu.

- Hi : Jenis saluran pemasaran lebih dari satu.

Bila saluran pemasaran lebih dari 1 jenis maka hipotesis diterima (Hi) dan Ho ditolak, artinya terdapat beberapa jenis saluran pemasaran. Apabila saluran pemasaran hanya 1 jenis maka hipotesis (Hi) ditolak dan Ho diterima.

Untuk menguji hipotesis (2) diuji dengan analisis deskriptif, hipotesis yang digunakan adalah :

Ho : Tidak ada perbedaan fungsi pemasaran yang dilakukan melalui setiap saluran pemasaran.

- Hi : Terdapat perbedaan fungsi pemasaran yang dilakukan melalui setiap saluran pemasaran

Bila terdapat perbedaan pelaksanaan fungsi pemasaran pada setiap saluran maka hipotesis

diterima (Hi) dan Ho ditolak. Jika tidak terdapat perbedaan pelaksanaan fungsi pemasaran pada setiap saluran maka hipotesis (Hi) ditolak dan Ho diterima. Untuk menguji hipotesis (3), dengan menghitung share margin untuk setiap saluran pemasaran.

Dari hasil tersebut, dapat diketahui besar margin keuntungan yang diterima masing-masing lembaga pemasaran. Hipotesis yang digunakan adalah :

Ho : Share margin profit produsen sama untuk setiap saluran pemasaran

$\mathrm{Hi}$ : Share margin profit produsen berbeda untuk setiap saluran pemasaran

Rumus menghitung margin pemasaran adalah :

$\mathrm{Mji}=\mathrm{Cij}+7 \mathrm{ti}$

Atau

$\mathrm{Mji}=\mathrm{Psi}-\mathrm{Pbi}$

Maka akan diperoleh pemasaran total:

$\mathrm{Mj}=\sum \mathrm{Mji}$

Keterangan:

$\mathrm{Mj} \quad=$ Margin pemasaran modal

$\mathrm{Mji} \quad=$ Margin pada lembaga pemasaran $\mathrm{ke}-\mathrm{i}$

Psi = Harga penjualan pada lembaga pemasaran $\mathrm{ke}-\mathrm{i}$

$\mathrm{Pbi}=$ Harga pembelian pada lembaga pemasaran ke-i

Cij = Biaya pemasaran untuk melaksanakan fungsi pemasaran ke-i oleh lembaga pemasaran ke-j

$\mathrm{Hi}=$ Keuntungan lembaga pemasaran ke- $\mathrm{i}$ 


\section{P-ISSN: 2527-8479 E-ISSN: 2686-2174}

Margin pemasaran terdiri dari biaya-biaya umtuk melakukan fungsi-fungsi pemasaran dan keuntungan lembaga pemasaran. Margin pemasaran yang tinggi tidak selalu mengindikasikan keuntungan yang tinggi, tergantung berapa besar biaya-biaya yang haras dikeluarkan lembaga-lembaga pemasaran untuk melakukan fungsi-fungsi pemasaran (Sudiyono, 2004).

Untuk menghitung bagian yang diterima oleh masing-masing lembaga pemasaran (share margin) digunakan rumus :

$$
\mathrm{Sm}=\frac{\mathrm{Pp}}{\mathrm{Pk}} \times 100 \%
$$

Keterangan :

$\mathrm{Sm}=$ Share Margin (\%)

$\mathrm{Pp}=$ Harga yang diterima produsen dan pedagang $(\mathrm{Rp})$

$\mathrm{Pk}=$ Harga yang dibayar oleh konsumen $(\mathrm{Rp})$

Price spread diperoleh dengan mengelompokkan biaya-biaya pemasaran menurut komponen biaya yang sama.Jika share margin produsen pada setiap saluran pemasaran berbeda, maka Hi diterima dan Ho ditolak. Apabila share margin produsen pada setiap saluran pemasaran adalah sama, maka Hi ditolak dan Ho diterima.

Hipotesis (4) dihitung dengan menggunakan analisis tabulasi sederhana, hipotesis yang digunakan adalah :

Ho : belum efisien (Ep $>50 \%)$

Hi : sudah efisien $(\mathrm{Ep}<50 \%)$

Menurut Soekartawi, 2002 rumus untuk menghitung efisiensi pemasaran:

$\mathrm{Ep}=\frac{\text { BIaya Pemasaran }}{\text { Nilai produk yang dipasarkan }} \times 100 \%$

Bila nilai Ep < 50\%, maka Hi diterima dan Ho ditolak. Artinya, pemasaran di daerah penelitian sudah efisien. Bila nilai Ep> 50\%, maka Hi ditolak dan Ho diterima.

\section{PEMBAHASAN}

\section{Pemasaran Buah Jeruk}

\section{Saluran Pemasaran}

a. Saluran I : Produsen $\rightarrow$ Konsumen

Pada saluran I ini dapat digambarkan skemanya seperti pada Gambar 1.

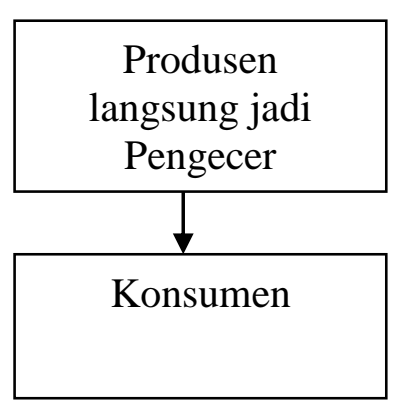

$\rightarrow=$ Pelaksanaan fungsi-fungsi pemasaran

Gambar 1.

Skema saluran I pemasaran jeruk. 


\section{Media Agribisnis}

\section{Vol. 3, Issue 2, November 2019}

\section{P-ISSN: 2527-8479 E-ISSN: 2686-2174}

Jumlah petani sampel 30, dari 30 orang ada 13 orang yang melakukan saluran pemasaran I. Petani yang tidak begitu luas kebun jeruknya mempunyai saluran pemasaran yang sangat sederhana. Pada saluran I ini produsen jeruk langsung menjual buah jeruk ke Pasar Nugraha atau Pasar Wameo. Jumlah buah jeruk yang dijual selama sebulan terakhir adalah $450 \mathrm{~kg}$ dengan harga Rp.4.500 per kg. Pemasaran buah jeruk dalam saluran I tidak kontinyu, kadang-kadang produsen petani tidak mempunyai waktu menjual buah jeruk sehingga mereka tidak menjual buah jeruknya. Mereka menjual buah jeruk ke pedagang pengecer atau ke pedagang pengumpul. Pada umumnya pada saluran I harga jual bagi petani produsen adalah yang paling tinggi dan share margin yang paling tinggi. Produsen hanya membayar ongkos/biaya transportnya dari Desa Lasembangi sampai pasar Nugraha atau pasar wamaeo dan biaya retribusi. Bagi petani produsen jeruk lain juga sebenamya berkeinginan melakukan penjualan buah jeruknya seperti dalam saluran I ini. Tetapi karena waktu ke pasar dirasakan kurang efisien dan volurnanya (penjualan) pada saluran I cukup kecil maka tidak dilakukan petani.

b. Saluran II : Produsen $\rightarrow$ Pedagang Pengecer $\rightarrow$ Konsumen

Saluran II ini dapat digambarkan skemanya seperli pada Gambar 2.

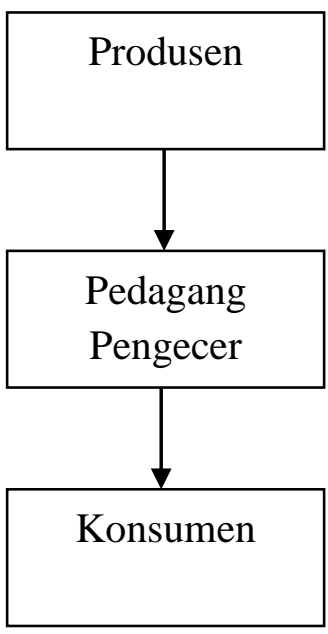

$\rightarrow=$ Pelaksanaan Fungsi-Fungsi Pemasaran

\section{Gambar 2.}

Skema saluran II pemasaran jeruk.

Jumlah jeruk yang dipasarkan selama sebulan terakhir adalah $2100 \mathrm{~kg}$ dengan harga Rp. 4000 per kg. Harga yang dibayar oleh konsumen sebesar Rp.5500 per kg. Buah dipasarkan oleh 6 orang pedagang pengecer. Produsen (petani sampel) yang terlibat dalam saluran II pemasaran jeruk ini ada 11 orang.

Pedagang pengecer ini langsung membeli buah jeruk ke petani jeruk/produsen, dan mereka menjualnya secara mengecer di Kota Baubau. Pedagang pengecer membayar harga buah jeruk secara kontan kepada produsen. 


\section{P-ISSN: 2527-8479 E-ISSN: 2686-2174}

c. Saluran III : Produsen $\rightarrow$ Pedagang Pengumpul $\rightarrow$ Konsumen

Saluran III ini dapat digambarkan skemanya seperti pada Gambar 3.

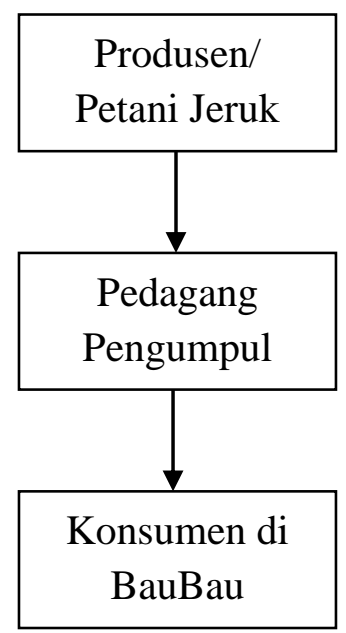

$\rightarrow=$ Pelaksanaan Fungsi-Fungsi Pemasaran

Gambar 3.

Skema Saluran III Pemasaran Jeruk

Saluran pemasaran produsen menjual buah jeruk pedagang pengumpul sebanyak $1.370 \mathrm{~kg}$, dengan harga Rp. 3800 per kg dalam sebulan. Harga yang hari dibayar oleh konsumen sebesar Rp.6000 per kg. Pedagang pengumpul ini langsung membawanya ke Baubau dan langsung dijual secara mengecer di Pasar Nugraha dan Wameo. Pedagang pengumpul ini langsung menjualnya secara ecerar. Berdasarkan uraian pada salurar pemasaran di atas maka hipotesis dalam penelitian ini yang menyatakan bahwa di daerah penelitian terdapat beberapa macam atau jenis saluran pemasaran jeruk dapat diterima.

\section{Fungsi-Fungsi Pemasaran}

Fungsi-fungsi pemasarar merupakan hal yang penting dalar proses pemasaran buah jeruk. Setiap lembaga pemasaran melakukan fungsinya sesuai dengan kebutuhan lembaga itu. Dari hasil penelitian diperoleh fungsi-fungsi pemasaran yang dilakukan oleh setiap lembaga pemasaran jeruk di setiap jenis saluran pemasaran. Adapun fungsi- fungsi pemasaran buah jeruk dapat dilihat pada Tabel 1.

Tabel 1. Fungsi-Fungsi Pemasaran Buah Jeruk di Saluran I

\begin{tabular}{c|l|c|c}
\hline No & \multicolumn{1}{|c|}{ Fungsi Pemasaran } & Produsen & Konsumen \\
1 & Pembelian & $\mathrm{T}$ & $\mathrm{Y}$ \\
2 & Penjualan & $\mathrm{Y}$ & $\mathrm{T}$ \\
3 & Penyimpanan & $\mathrm{Y}$ & $\mathrm{T}$ \\
4 & Transportasi & $\mathrm{Y}$ & $\mathrm{T}$ \\
5 & Standarisasi Soriasi & $\mathrm{Y}$ & $\mathrm{T}$ \\
\hline
\end{tabular}




\section{P-ISSN: 2527-8479 E-ISSN: 2686-2174}

\begin{tabular}{c|l|c|c}
\hline 6 & Pembiayaan & $\mathrm{Y}$ & $\mathrm{T}$ \\
7 & Penanggungan resiko & $\mathrm{Y}$ & $\mathrm{T}$ \\
8 & Informasi pasar & $\mathrm{Y}$ & $\mathrm{T}$ \\
9 & Pengepakan & $\mathrm{Y}$ & $\mathrm{T}$ \\
\hline
\end{tabular}

Ket : $Y=$ Ya, melakukan,

$\mathrm{T}=$ Tidak melakukan

Berdasarkan Tabel 1 dapat diketahui bahwa pada saluran pemasaran I produsen yang sekaligus pengecer melakukan 8 fungsi pemasaran yaitu: penjualan, penyimpanan, transportasi, standarisasi, pembiayaan, penanggungan resiko, informasi pasar dan pengepakan. Hanya satu fungsi yang tidak dilakukan produsen ini yaitu pembelian buah jeruk karena jeruk yang dijual adalah miliknya sendiri. Sedangkan konsumen hanya melakukan fungsi pembelian yaitu membeli buah jeruk. Fungsi penyimpanan pada saluran I tidak selamanya dilakukan, apabila jeruk habis terjual pada hari itu maka tak ada buah yang disimpan.

Saluran pemasaran II pedagang pengecer melakukan 9 fungsi pemasaran yaitu: pembelian, penjualan, penyimpanan, transportasi, standarisasi sortasi, pembiayaan, penanggungan resiko, informasi pasar dan pengepakan. Produsen melakukan fungsi penjualan. Konsumen hanya melakukan fungsi pembelian yaitu membeli buah jeruk. Pelaksanaan fungsi pemasaran di saluran II dapat dilihat pada Tabel 2.

Tabel 2. Fungsi-Fungsi Pemasaran Buah Jeruk di Saluran II

\begin{tabular}{clcc}
\hline No & \multicolumn{1}{c}{ Fungsi Pemasaran } & Produsen & Konsumen \\
\hline 1 & Pembelian & $\mathrm{Y}$ & $\mathrm{Y}$ \\
\hline 2 & Penjualan & $\mathrm{Y}$ & $\mathrm{T}$ \\
\hline 3 & Penyimpanan & $\mathrm{Y}$ & $\mathrm{T}$ \\
\hline 4 & Transportasi & $\mathrm{Y}$ & $\mathrm{T}$ \\
\hline 5 & Standarisasi Soriasi & $\mathrm{Y}$ & $\mathrm{T}$ \\
\hline 6 & Pembiayaan & $\mathrm{Y}$ & $\mathrm{T}$ \\
\hline 7 & Penanggungan resiko & $\mathrm{Y}$ & $\mathrm{T}$ \\
\hline 8 & Informasi pasar & $\mathrm{Y}$ & $\mathrm{T}$ \\
\hline 9 & Pengepakan & $\mathrm{Y}$ & $\mathrm{T}$ \\
\hline
\end{tabular}

Ket: $Y=$ Ya, melakukan,

$\mathrm{T}=$ Tidak melakukan

Saluran pemasaran III pedagang pengumpul melakukan 9 fungsi pemasaran yaitu: pembelian, penjualan, penyimpanan. transportasi, standarisasi/sortasi, pembiayaan, 
penanggungan resiko, informasi pasar dan pengepakan buah jeruk. Produsen melakukan fungsi penjualan dan konsumen hanya melakukan fungsi pembelian. Karena pada saluran III buah jeruk dijual ke kota Baubau (Pasar Nugraha dan Pasar Wameo) maka terlebih dahulu dilakukar pengepakan atau penempatan dalai" keranjang tertentu. Keranjang buah jeruk ini berfungsi untuk mencegah kerusakan buah dalam perjalanan. Fungsi-Fungsi Pemasaran Buah Jeruk di Saluran III seperti pada Tabel 3.

Tabel 3. Fungsi-Fungsi Pemasaran Buah Jeruk di Saluran III

\begin{tabular}{clcc}
\hline No & \multicolumn{1}{c}{ Fungsi Pemasaran } & Produsen & Konsumen \\
\hline 1 & Pembelian & $\mathrm{Y}$ & $\mathrm{Y}$ \\
\hline 2 & Penjualan & $\mathrm{Y}$ & $\mathrm{T}$ \\
\hline 3 & Penyimpanan & $\mathrm{Y}$ & $\mathrm{T}$ \\
\hline 4 & Transportasi & $\mathrm{Y}$ & $\mathrm{T}$ \\
\hline 5 & Standarisasi Soriasi & $\mathrm{Y}$ & $\mathrm{T}$ \\
\hline 6 & Pembiayaan & $\mathrm{Y}$ & $\mathrm{T}$ \\
\hline 7 & Penanggungan resiko & $\mathrm{Y}$ & $\mathrm{T}$ \\
\hline 8 & Informasi pasar & $\mathrm{Y}$ & $\mathrm{T}$ \\
\hline 9 & Pengepakan & $\mathrm{Y}$ & $\mathrm{T}$ \\
\hline
\end{tabular}

Ket : $\mathrm{Y}=\mathrm{Ya}$, melakukan,

$\mathrm{T}=$ Tidak melakukan

Berdasarkan uraian pada fungsi-fungsi pemasaran tersebut, maka hipotesis II ditolak. Tidak ada catatan pada petani produsen jeruk tentang jumlah buah yang tidak layak dijual. Ada petani mengatakan sekitar $10 \%$ dari jumlah produksi per tahun tidak layak untuk dijual, ada pula yang mengatakan sekitar 5\% dari jumlah produksi per tahun tidak layak untuk dijual.

\section{Marketing Margin dan Price Spread}

Marketing margin ada selisih antara harga yang diterima produsen dengan harga yang dibayar oleh konsumen. Marketing margin untuk setiap saluran pemasaran buah jeruk dapat dilihat pada tabel 4,5 , dan 6 . Saluran pemasaran I produsen langsung menjual buah jeruknya ke konsumen, artinya tidak melalui lembaga perantara dalam memasarkan hasilnya. Oleh karena itu, share margin biaya pemasaran cukup kecil yakni hanya 4,98\%. yang terdiri dari biaya transport $2,99 \%$ dan biaya retribusi adalah $1,33 \%$. Share margin biaya pengepakan sebesar $66 \%$. Biaya pengepakan ini adalah biaya yang dikeluarkan petani untuk menyewa keranjang. Biaya produksi produsen adalah $61,11 \%$ dan share profit produsen dalam saluran pemasaran I adalah $33.90 \%$ dapat dilihat pada Tabel 4.

Tabel 4. Marketing Margin dan Share Margin Pada Saluran I

$$
\text { Uraian Price Spread(Rp/kg) Share Margin (\%) }
$$




\section{Media Agribisnis}

Vol. 3, Issue 2, November 2019

\section{P-ISSN: 2527-8479 E-ISSN: 2686-2174}

\begin{tabular}{lcc}
\hline Harga jual produsen & 4.500 & 100 \\
\hline Biaya Produksi & 2.750 & 61,11 \\
\hline Biaya Transport & 134,62 & 2,99 \\
\hline Biaya Retribusi & 59,92 & 1,33 \\
\hline Biaya Pengepakan & 29,77 & 0,66 \\
\hline Biaya Pemasaran & 224,31 & 4,98 \\
\hline Profit Produsen & $1.525,69$ & 33,90 \\
\hline Harga beli konsumen & 4.500 & 100
\end{tabular}

Share margin harga jual produsen, price spread dan share margin profit pedagang pengecer serta marketing margin pada saluran pemasaran II dapat dilihat pada Tabel 5.

Tabel 5. Marketing Margin dan Share Margin pada Saluran II

Uraian Price Spread (Rp/kg) Share Margin (\%)

\begin{tabular}{|c|c|c|}
\hline Harga jual produsen & 4.000 & 72,73 \\
\hline - Biaya Produksi & 2.751 & 50,02 \\
\hline - Biaya Transport & 162 & 2,95 \\
\hline - Biaya Retribusi & 0 & 0,00 \\
\hline - Biaya Pemasaran & 162 & 2,95 \\
\hline - Profit Produsen & 1.087 & 19,76 \\
\hline Harga beli Pengecer & 4.000 & 72,73 \\
\hline - Transportasi & 180 & 3,27 \\
\hline - $\quad$ Retribusi & 105 & 1,91 \\
\hline - Biaya Pengepakan & 40 & 0,73 \\
\hline - Biaya Pemasaran & 325 & 5,91 \\
\hline - Profit Pengecer & 1.175 & 21,36 \\
\hline Marketing Margin & 1.500 & 27,27 \\
\hline Harga beli konsumen & 5.500 & 100 \\
\hline
\end{tabular}




\section{P-ISSN: 2527-8479 E-ISSN: 2686-2174}

Share margin harga jual produsen adalah $72,73 \%$, share margin biaya produksi adalah $50,02 \%$ dan profit margin produsen adalah $19,76 \%$. Pedagang pengecer mempunyai profit dengan price spread sebesar Rp.1.175,- atau share margin profit sebesar $21.36 \%$. Share margin biaya pengepakan sebesar $0,73 \%$. Biaya pengepakan adalah biaya yang dikeluarkan pedagang pengecer untuk menyewa keranjang. Price spread dan share margin profit pedagang pengecer termasuk besar. Harga beli konsumen pada saluran pemasaran II ini adalah Rp.5.500 maka diperoleh besarnya marketing margin adalah Rp. 1.500 atau dengan share margin sebesar $27,27 \%$.

Share margin harga jual produsen,price spread dan share margin profit pedagang pengumpul serta marketing margin pada saluran pemasaran III dapat dilihat pada Tabel 6.

Tabel 6. Marketing Margin dan Share Margin Pada Saluran III.
Uraian Price Spread (Rp/kg)
Share Margin (\%)

\begin{tabular}{lcc}
\hline Harga jual produsen & 3.800 & 63,33 \\
\hline- Biaya Produksi & 2.751 & 45,85 \\
\hline- Biaya Transport & 0 & 0,00 \\
\hline$-\quad$ Biaya Retribusi & 0 & 0,00 \\
\hline$-\quad$ Biaya Pemasaran & 0 & 0,00 \\
\hline- Profit Produsen & 1.049 & 17,48 \\
\hline Harga beli Pengecer & 3.800 & 63,33 \\
\hline$-\quad$ Transportasi & 563 & 9,38 \\
\hline$-\quad$ Retribusi & 47,33 & 0,79 \\
\hline$-\quad$ Biaya Pengepakan & 96,67 & 1,61 \\
\hline$-\quad$ Biaya Pemasaran & 707 & 11,78 \\
\hline$-\quad$ Profit Pengecer & 1.493 & 24,88 \\
\hline Marketing Margin & 2.200 & 36,67 \\
\hline Harga beli konsumen & 6.000 & 100 \\
\hline
\end{tabular}

Berdasarkan Tabel 6 dapat diketahui bahwa price spread harga jual produsen adalah Rp. 3.800 per kg dengan share margin adalah 63,33\%. Price spread biaya produksi adalah Rp. 2.751 dengan share margin $45,85 \%$, dan biaya pemasaran tidak ada bagi produsen. Profit produsen dengan price spread Rp. 1.049 per kg dengan share margin adalah 17,48\%.

Harga beli pedagang pengumpul adalah Rp. 3.800 per kg dengan share margin 63,33\% dan biaya pemasaran adalah Rp. 707 per kg dengan share margin adalah 11,78\%. Biaya pengepakan sebesar $1,61 \%$, biaya pengepakan adalah biaya yang dikeluarkan pedagang 
pengumpul untuk memheli keranjang. Profit pedagang pengumpul adalah Rp. 1.493 per $\mathrm{kg}$ dengan share margin 24,88\%, marketing margin adalah Rp. 2.200 dengan share margin adalah 36,67\%. Harga beli konsumen pada saluran III ini adalah Rp. 6.000 per kg.

Berdasarkan uraian marketing margin profit produsen dan share margin dapat dilihat atau diketahui besarnya share margin profit produsen di setiap saluran pemasaran yaitu:

Pada saluran I: $\quad$ price spread Rp. 1.525,69/kg share margin adalah 33,90\%.

Pada saluran II: $\quad$ price spread Rp. $1.087 / \mathrm{kg}$ share margin adalah $19,76 \%$.

Pada saluran III: $\quad$ price spread $\mathrm{Rp} .1 .049 / \mathrm{kg}$ share margin adalah $17,48 \%$.

Berdasarkan uraian diatas dapat dilihat bahwa share margin profit produsen paling besar pada saluran pemasaran I, menyusul pada saluran pemasaran II dan paling kecil terdapat pada saluran pemasaran III. Perbedaan ini terutama disebabkan perbedaan tingkat harga jual tomat ke pedagang dan ke konsumen, selain itu disebabkan biaya pemasaran. Telah diketahui bahwa pada saluran pemasaran I biaya pemasaran sangat kecil, karena petani (produsen) yang langsung menjual produksinya (tanpa perantara) ke pasar.

\subsubsection{Efisiensi Pemasaran}

Efisiensi pemasaran dapat dihitung dengan ratio biaya pemasaran dibagi dengan harga jual, kemudian dikalikan dengan 100\%, ini disebut dengan Ep. Makin kecil Ep maka semakin efisien pemasaran itu. Dari uraian sebelumnya telah diperoleh angka biaya pemasaran dan harga jual pada setiap saluran pemasaran. Angka biaya pemasaran dan harga jual serta efisiensi saluran pemasaran dapat dilihat pada Tabe 71 berikut:

Tabel 7. Efisiensi Pemasaran pada Setiap Saluran Pemasaran

\begin{tabular}{cccc}
$\begin{array}{c}\text { Saluran } \\
\text { Pemasaran }\end{array}$ & $\begin{array}{c}\text { Biaya Pemasaran } \\
(\mathrm{Rp} / \mathrm{kg})\end{array}$ & $\begin{array}{c}\text { Harga Jual } \\
\mathrm{Rp} / \mathrm{kg}\end{array}$ & Ep (\%) \\
\hline $\mathrm{I}$ & 224,31 & 4500 & 4,98 \\
\hline 11 & 487 & 5500 & 8,85 \\
\hline 111 & 707 & 6000 & 11,78 \\
\hline
\end{tabular}

Berdasarkan Tabel 7 diatas dapat dilihat bahwa yang paling efisien pemasarannya terdapat pada saluran pemasaran I dengan Ep hanya 4,98\%. Kemudian saluran pemasaran ke II dengan nilai Ep adalah 8,85\% menyusul saluran pemasaran III dengan Ep adalah 11,78\%. Oleh karena nilai EP di setiap saluran pemasaran adalah lebih kecil daripada $50 \%$, maka hipotesis ke 4 dalam penelitian ini dapat diterima, yaitu pemasaran buah jeruk di Desa Lasembangi Kecamatan Lasalimu sudah efisien.

\section{KESIMPULAN DAN SARAN}

\section{Kesimpulan}

Kesimpulan dari penelitian ini adalah:

Terdapat 3 macam atau 3 jenis saluran pemasaran di daerah penelitian ini yaitu saluran I: Petani produsen $\rightarrow$ Konsumen, saluran II: Produsen $\rightarrow$ Pedagang Pengecer $\rightarrow$ Konsumen, dan saluran III: Produsen $\rightarrow$ Pedagang Pengumpul $\rightarrow$ Konsumen. 
Fungsi-fungsi pemasaran yang dilakukan pada setiap saluran pemasaran adalah sama.

1. Share margin profit produsen adalah berbeda-beda untuk setiap saluran pemasaran. Share margin saluran I 33,90\%, saluran II 19,76\% dan saluran III 17,48\%.

2. Saluran pemasaran jeruk siam di Desa Lasembangi sudah efisien.

\section{Saran}

Beberapa saran dalam penelitian ini adalah:

1. Petani disarankan menjual langsung jeruk siam ke konsumen tanpa melalui agen sehingga harga jual jeruk menjadi lebih tinggi dan keuntungan petani lebih tinggi.

2. Petani perlu membentuk koperasi pemasaran jeruk, sedapat mungkin diusahakan peran pedagang seminim mungkin.

\section{DAFTAR PUSTAKA}

Ashari. S., 2004. Biologi Reproduksi Tanaman Buah - Buahan Komersial. Bayumedia. Jakarta Timur.

Ginting. A., 2006. Petani Karo Jantungan Takut tak Terjual di Pasar. SIB, Medan.

Hidayat. A.R., 2006. Disparitas Harga Jeruk. Kompas, Medan.

Joesoef. M., $\quad$ 1993. Penuntun Berkebun Jeruk. Bhratara. Jakarta.

Rahardi. F., H. Indriani dan Haryono, 2004. Agribisnis Tanaman Buah. Penebar Swadaya, Jakarta.

Soekartawi, 2002. Prinsip Dasar Manajemen Pemasaran Hasil-Hasil $\quad$ Pertanian. $\quad$ PT. RajaGrafindo Persada. Jakarta.

Sudiyono, A., 2004. Pemasaran Pertanian. UMM Press. Malang. 